\title{
The complement system and obesity-associated metabolic disorders
}

Citation for published version (APA):

Xin, Y. (2019). The complement system and obesity-associated metabolic disorders: The CODAM study. [Doctoral Thesis, Maastricht University]. Gildeprint Drukkerijen. https://doi.org/10.26481/dis.20190925xy

Document status and date:

Published: 01/01/2019

DOI:

10.26481/dis.20190925xy

Document Version:

Publisher's PDF, also known as Version of record

\section{Please check the document version of this publication:}

- A submitted manuscript is the version of the article upon submission and before peer-review. There can be important differences between the submitted version and the official published version of record.

People interested in the research are advised to contact the author for the final version of the publication, or visit the DOI to the publisher's website.

- The final author version and the galley proof are versions of the publication after peer review.

- The final published version features the final layout of the paper including the volume, issue and page numbers.

Link to publication

\footnotetext{
General rights rights.

- You may freely distribute the URL identifying the publication in the public portal. please follow below link for the End User Agreement:

www.umlib.nl/taverne-license

Take down policy

If you believe that this document breaches copyright please contact us at:

repository@maastrichtuniversity.nl

providing details and we will investigate your claim.
}

Copyright and moral rights for the publications made accessible in the public portal are retained by the authors and/or other copyright owners and it is a condition of accessing publications that users recognise and abide by the legal requirements associated with these

- Users may download and print one copy of any publication from the public portal for the purpose of private study or research.

- You may not further distribute the material or use it for any profit-making activity or commercial gain

If the publication is distributed under the terms of Article $25 \mathrm{fa}$ of the Dutch Copyright Act, indicated by the "Taverne" license above, 


\section{Chapter 7}

Summary and general discussion 
Obesity is a worldwide epidemic, affecting not only adults but nowadays also children and adolescents. Globally, about 39\% of adults are overweight, $13 \%$ of adults are obese, and over 18\% of children and adolescents are overweight or obese in 2016 (World Health Organization (1)). People with obesity are at high risk of chronic metabolic disorders such as dyslipidaemia, hypertension, metabolic syndrome, type 2 diabetes mellitus (T2DM), and cardiovascular disease (CVD) (2). Obesity is also associated with increased mortality from various causes, in particular CVD (3). According to the literature, about 4 million of deaths worldwide among adults were attributable to overweight and obesity in 2015, of which the most common cause was CVD (4). The higher presence of obesity and associated comorbid conditions leads to increased morbidity, mortality, which will cause higher medical and economic burdens. Therefore, exploration of the aetiology for obesity and related comorbid diseases is urgently needed.

The complement system is part of the innate immune system and, as such, a system for host defence. It is now becoming increasingly clear that complement is also involved in whole body homeostasis and metabolism. Many complement factors can be produced by adipose tissue as well as other metabolic organs such as the liver and the pancreas and can contribute to metabolic (dys)regulation $(5,6)$. Until recently, human studies on the associations between the complement system and metabolic disorders were mostly focused on the central complement component, C3 (7-9). Activation of C3 results from activation of the classical, the alternative, or the lectin pathway, and can lead to activation of the terminal pathway (10). Previous work from our group and others has indicated distinct roles of these complement pathways in metabolic disorders in humans. Most of these studies pointed towards an adverse association of the alternative pathway (11-13), while a few showed also adverse associations of classical and terminal pathway activation, with metabolic disorders (8). The lectin pathway was reported to play a dual role especially in insulin resistance and CVD $(8,14)$. Therefore, the major objective of this thesis was to investigate the associations of the components involved in activation of the alternative pathway, and to some extent also the classical and terminal pathway, with obesity and related metabolic disorders, such as dyslipidaemia, metabolic syndrome, and T2DM. Our studies were performed in a human observational cohort study, the CODAM study. In this 
final chapter, we summarize the main findings and place them in the context of the available literature. We additionally discuss possible methodological considerations in our studies, and address several future research directions.

\section{Main findings}

In chapter 2, we investigated longitudinal associations of complement components of the alternative $(\mathrm{C} 3, \mathrm{C} 3 \mathrm{a}, \mathrm{Bb}$, factor $\mathrm{D}$, factor $\mathrm{H}$, and properdin) and terminal ( $\mathrm{C} 5 \mathrm{a}$, sC5b-9) pathways with adiposity (BMI and waist circumstance). We found that, during a 7-year period, higher baseline plasma concentrations of most alternative pathway components (i.e. C3, C3a, factor $\mathrm{D}$, factor $\mathrm{H}$, and properdin), but not $\mathrm{Bb}$, an alternative pathway activation product, were associated with more adiposity, i.e. higher BMI and waist circumstance. The terminal pathway activation products (i.e. C5a, or sC5b-9) were not associated with the development of adiposity. These observations point towards a role for the alternative pathway of complement activation in the development of human obesity. This may be attributed to the effect of C3-C3a-C3adesarg/ASP axis on lipid metabolism and adipocyte differentiation that was demonstrated in previous experimental studies $(5,15)$. We further evaluated the associations between changes in complement concentrations and changes in adiposity over time. These latter analyses were performed for C3, factor D, factor $\mathrm{H}, \mathrm{C} 5 \mathrm{a}$, and sC5b-9. We only observed significant positive associations for $\mathrm{C} 3$ and factor $\mathrm{H}$. This observation suggests that the longitudinal association of $\mathrm{C} 3$ and factor $\mathrm{H}$ with adiposity may reflect both within-individual changes and interindividual differences during the 7-year period (16). For factor $D$, the longitudinal association with adiposity was mainly attributed to interindividual differences that remained consistent over time. These findings indicate that the longitudinal associations of various aspects of the alternative complement pathway with adiposity may be attributed to distinct underlying mechanisms.

Abnormality in plasma lipids and lipoproteins is an important risk factor for various metabolic disorders that are often seen in obesity (17). In chapter $\mathbf{3}$, the associations between the complement system and plasma lipoproteins were investigated. For this, we investigated the cross-sectional associations of the central complement component, C3, 
and other complement regulators and activation products of the alternative pathway (C3a, $\mathrm{Bb}$, factor $\mathrm{D}$, factor $\mathrm{H}$, properdin, and MASP-3) with the distribution and lipid composition of 14 lipoprotein subclasses. We showed that a higher concentration of C3 was associated with an adverse lipoprotein distribution and composition, i.e. more TG-enriched lipoproteins and fewer larger-sized HDL lipoproteins. Consistent but weaker associations were observed for properdin, factor $\mathrm{H}$, factor $\mathrm{D}$, and MASP-3 (effect size in descending order). In addition, we found that the associations for most components (i.e. properdin, factor $\mathrm{D}$, and MASP-3 but not factor $\mathrm{H}$,) were largely independent of $\mathrm{C} 3$. If we take into account the lack of associations for the alternative pathway activation products (i.e. C3a and $\mathrm{Bb}$ ), it is possible that instead of representing the activation of the alternative pathway, these complement components may themselves play a distinct role in lipid and lipoprotein metabolism. Although the underlying mechanisms are not fully understood, the causal role of some complement proteins in lipid metabolism has been demonstrated in several genetically modified animal models (18-20). We found that the observed associations with lipoproteins were (largely) independent of obesity, insulin resistance, low-gradeinflammation, and liver enzymes, the major biological pathways that are involved in lipid and lipoprotein metabolism. Previous human studies demonstrated the presence of complement proteins on plasma VLDL, LDL, and HDL lipoproteins, of which C3 was the most dominant complement component (21-23). This raises the possibility that complement components, especially C3, could have a direct physical effect on the metabolism of these lipoproteins, which might lead to an altered distribution and composition of the lipoprotein subclasses. In addition, it has been shown that under pathological conditions, plasma HDL can be modified into a dysfunctional, pro-inflammatory particle that contains more inflammatory proteins (24). In line with this, our results suggest that some (dysfunctional) lipoprotein subfractions may have substantial affinity for binding complement components $(22,24)$. Taken together, our observations suggest that the alternative complement pathway, especially C3, was associated with a pro-atherogenic lipoprotein profile. This may be a possible mechanism through which these complement components can contribute to dyslipidaemia and cardiometabolic disorders. 
In chapter 4, we investigated the cross-sectional and prospective associations of complement proteins, regulators and activation products from the alternative (i.e. C3, C3a, $\mathrm{Bb}, \mathrm{FD}, \mathrm{FH}$, and properdin) and classical (i.e. $\mathrm{C} 1 \mathrm{q}, \mathrm{C} 1-\mathrm{INH}$, and $\mathrm{C4}$ ) pathway, with prevalence and incidence of the metabolic syndrome. We showed that not only C3 and C4 but also several regulators and activation products of the alternative pathway (i.e. $\mathrm{C} 3 a$, factor $\mathrm{H}$, and properdin) are indeed positively associated with the prevalence of the metabolic syndrome. However, in the prospective analyses, only complement C3 and C4, but none of their regulators or activation products, were associated with the development of the metabolic syndrome. This suggests that the relation of C3 and C4 with the development of the metabolic syndrome might be independent of traditionally recognized complement activation. For instance, recent findings showed that C3 could be activated intracellularly by cathepsin L, without the presence of C3 convertase, and this intracellular activation of C3 was involved in T-cell homeostasis (25). This suggests a specific biological effect of C3, that is independent of complement proteins and regulators of the activation pathways. We also explored potential underlying mechanisms for the associations we observed for C3 and C4 with incident metabolic syndrome. We found that the prospective association for $\mathrm{C} 3$ can be explained by the baseline profile of components of the metabolic syndrome, as well as plasma concentrations of liver enzymes. Thus, higher baseline C3 concentration was related to a worse metabolic profile and probably also related to impaired liver function, via which it promotes the development of metabolic syndrome. However, the prospective association for C4 was independent of the baseline metabolic syndrome profile and also independent of the other potential pathways that were explored. This may suggest that C3 and C4 have distinct effects on (metabolic) pathways that lead to development of the metabolic syndrome.

In chapter 5, we evaluated longitudinal associations of components of the alternative complement pathway (C3, C3a, Bb, factor $\mathrm{D}$, factor $\mathrm{H}$, properdin, and MASP-3) with insulin sensitivity/resistance (Matsuda index, Stumvoll's index, and HOMA2-IR), $\beta$-cell function (basal and overall insulin secretion rate, $C$-peptidogenic index, $\beta$-cell glucose sensitivity, $\beta$ cell potentiation, and $\beta$-cell rate sensitivity), and T2DM. The most prominent observation was that, over the 7-year period, a higher baseline C3 concentration was associated with 
less insulin sensitivity, indicating worse insulin resistance. This association was independent of several potential confounders and $\beta$-cell function. We also found that higher C3 was associated with more insulin secretion, which was largely attributed to insulin resistance. Although at first sight $\mathrm{C} 3$ also appeared to be associated with worse $\beta$-cell function, these associations were mostly confounded by other factors such as obesity, or related to insulin resistance. Similar but weaker associations were observed for several alternative pathway complement regulators, i.e. properdin, factor $\mathrm{H}$, and MASP-3 (effect size in descending order). One possible explanation for these observations is that the complement components may contribute to obesity-induced whole body insulin resistance via their proinflammatory properties, and at the same time may induce insulin secretion by islets to compensate for the inflammation-induced insulin resistance. In this way, complement may serve as a metabolic feedback system in response to insulin resistance (26). In addition, based on the available experimental data, mostly obtained in rodents, alternative pathway activation was anticipated to be positively associated with some measures of better $\beta$-cell function. In contrast, we found almost no associations for the activation product C3a and a positive association for another activation product $\mathrm{Bb}$ with insulin sensitivity. We hypothesized that this might be due to intrinsic differences between human and rodent islets, and that in humans it may be the activation of $\mathrm{C} 5$ and the terminal pathway, rather than C3 and the alternative pathway, that is associated with enhanced $\beta$-cell function. Lastly, C3 was the only complement factor that was found to be associated with the 7-year incidence of T2DM. This association was mediated by insulin resistance, but not by $\beta$-cell function. Taken together, these findings indicate multiple and dynamic roles of (activation of) alternative pathway in the development of T2DM in humans, which at the whole body level mainly points to an association with worse insulin resistance rather than better $\beta$-cell function.

The most prominent metabolic disturbance in T2DM is hyperglycaemia, which may underlie the development of various complications that are observed in T2DM patients. Hyperglycaemia can cause, among others, dicarbonyl stress $(27,28)$. In the circulation, dicarbonyl stress may be reflected by a higher presence of glycating agents, i.e. $\alpha$ dicarbonyls (e.g. MGO, GO, 3-DG), as well as related AGEs (e.g. free and protein-bound CML, 
CEL, free MG-H1, and protein-bound pentosidine) (27). Data in the literature suggested that the functionality of complement inhibitors is hampered by glycation (29-31) and glycated complement membrane inhibitors were observed in diabetes patients $(29,31,32)$. We therefore hypothesized that dicarbonyl stress may induce the glycation of complement inhibitors and impaired their regulatory function, leading to enhanced complement activation. In chapter 6, we explored the possible relationship of dicarbonyl stress with complement activation (as reflected by plasma levels of the activation products, C3a and sC5b-9). We found distinct associations of these markers of dicarbonyl stress with complement activation: in the whole population, GO was not associated with $\mathrm{C} 3 \mathrm{a}$ and was inversely associated with sC5b-9, while MGO, 3-DG, and free AGEs were not associated with either C3a or SC5b-9; protein-bound CEL and to some extent also protein-bound CML and pentosidine were inversely associated with $\mathrm{C} 3 \mathrm{a}$; and protein-bound pentosidine was positively associated with sC5b-9 while no associations were observed for protein-bound CML and CEL. We also found that the association of GO with SC5b-9 may be related to an ongoing inflammation process, and that the associations of protein-bound CML and pentosidine with C3a were explained by obesity, while the associations for protein-bound CEL with C3a and for pentosidine with sC5b-9 were independent of the potential confounders evaluated in our study. This suggests that these associations may be attributed to different underlying mechanisms. In line with this, we found that the presence of T2DM, which may lead to a higher burden of glycation and dicarbonyl stress, influenced some, but not all of, the association between dicarbonyl stress and complement activation. Notably, the positive association of protein-bound pentosidine with sc5b-9, which is the only association in this study that was in line with our hypothesis, was not influenced by diabetes status. Previous human studies indicated that plasma protein-bound pentosidine may better represent tissue AGE accumulation (33-35). Therefore, this positive association may reflect the effect of dicarbonyl stress on complement activation in tissues. In addition, when we evaluated associations of potential markers for life-long MGO stress, i.e. two functional polymorphisms in the MGO-detoxifying enzyme GLO1, the direction of association with complement activation was unexpected. Rs2736654 was not associated with either C3a or sc5b-9, while the genotypes that were reported to have less GLO1 activity (hence greater 
186 | Chapter 7

dicarbonyl stress) of $r s 1049346$, were associated with lower sC5b-9 concentration (hence less activation of the terminal pathway). Rs1049346 was also not associated with the C3a concentration. Overall, the associations of plasma dicarbonyl stress markers with complement activation, mostly pointed towards an inverse direction, except for proteinbound pentosidine. 